\title{
Un balance necesario: la evolución editorial en la Universidad Autónoma de Aguascalientes
}

JOSÉ DOMINGO CARRILLO

Departamento de Historia/UAA

I.

a proliferación de revistas académicas es uno de los rasgos más notables del crecimiento y la modernización de la educación superior. La posibilidad de conocer y conocerse a través de las publicaciones, implica para la comunidad universitaria un acontecimiento importante: significa medir sus alcances y limitaciones, a la vez que permite valorar la relación con el entorno, es decir, hasta dónde y cuánto la Universidad está presente en la sociedad.

La Universidad Autónoma de Aguascalientes ha transitado por varias etapas editoriales, buscando a través de esfuerzos departamentales, por centros, o individuales, una proyección hacia la sociedad, pero fundamentalmente un debate al interior del campus universitario; no obstante los buenos deseos, ¿llo ha conseguido?

Las siguientes líneas, tienen como propósito realizar un balance y una presentación crítica de las publicaciones de la Universidad hasta el día de hoy, balance necesario por cuanto la Universidad inicia un experimento: la edición de Caleidoscopio, publicación que pretende sintetizar los esfuerzos editoriales anteriores y consolidarse como una revista de polémica y presencia universitaria. 


\section{LOS ORÍGENES}

Voz Universitaria constituye la génesis de los esfuerzos editoriales de la Universidad Autónoma de Aguascalientes. Los primeros números aparecen en 1974 -algunos sin numeración ni fecha-, con una edición mensual y dedicada esencialmente a la divulgación del quehacer cotidiano de la Universidad.

Es frecuente encontrar en sus páginas información sobre becas, reflexiones sobre el significado del lema universitario y dar cuenta de algunos eventos sociales como la participación de estudiantes de la UAA, en el Festival de las madres en Tuxtla Gutiérrez, Chiapas.

En 1975 aparece cada dos meses manteniendo su sello característico: emitir todo tipo de información, sin orden temático. Esta revista nace con un concepto editorial difuso y sencillo: informar.

A partir de 1982, Voz Universitaria se presenta como la revista cultural de la Universidad. Acorde con esos aires, la revista se transforma básicamente en una publicación de naturaleza literaria, aunque no excluye la publicación de artículos sobre ciencias naturales y sociales.

En la década de los noventa inicia el principio del fin, los últimos números aparecen por estos años. Indudablemente la muerte del Dr. Desiderio Macías Silva, su principal animador, precipitó el fin de esta revista.

A la desaparición de Voz Universitaria, el Centro de Enseñanza Media, bajo la responsabilidad de Eduardo López, comenzó a publicar Tierra Baldía, revista de literatura que con una agradable presentación ha editado hasta el momento siete números.

Pero la Universidad de Aguascalientes necesitaba otra revista, con un concepto editorial diferente, volcada a difundir los avances de investigación que en centros y departamentos se ejecutan. Con ese propósito asomó, en el horizonte editorial, Investigación y Ciencia, que se presentaba como el órgano de "Divulgación Científica de la Universidad". 
Investigación y Ciencia apareció con una periodización cuatrimestral, pretendiendo construir el puente entre los investigadores y la comunidad universitaria.

No obstante ser una revista editada bajo la responsabilidad del Departamento de Apoyo a la Investigación y Educación Continua, su circulación era restringida. Se distribuían ejemplares únicamente entre los colaboradores y entre los investigadores con algún proyecto de investigación en marcha.

Investigación y Ciencia no era una revista especializada en cięncias sociales -campo que nos ocupa-, divulgando los avances de investigación y las colaboraciones de profesores/investigadores de la Universidad y de otras instituciones. Sin embargo, una limitada distribución impidió que la revista fuese conocida y asumida por la comunidad universitaria como propia.

Además de la deficiencia administrativa señalada anteriormente, algunos números fueron publicados con errores de edición, inadmisibles en una publicación institucional que reunía a los principales investigadores de la Universidad. ${ }^{1}$

El siguiente cuadro muestra el origen de los artículos de el centro de Artes y Humanidades y los de otros Centros de la Universidad, publicados en esta revista.

1. Me refiero a Investigación y Ciencia No.15, correspondiente a agosto de 1995 . En el índice, aparece el reporte preliminar sobre el padrón electrocardiográfico entre trabajadores docentes y administrativos de la Universidad. El lector busca afanosamente el artículo y, éste no aparece, porque ya había sido publicado en el No.13, del mes de diciembre de 1994. 
Fuente: Investigación y Ciencia, No. 19. pp. 67-74.

(a) Instituto Nacional de Antropología e Historia.

En el editorial de Investigación y Ciencia No. 19, correspondiente a diciembre de 1996, se afirma que se editaron 19 números con un total de 180 artículos. Sin embargo, un conteo elemental da por resultado 187 artículos.

La publicación de temas de ciencias sociales tiene un despegue a partir de 1993, manteniéndose en cantidades aceptables pero nunca supera a los avances de investigación de otros centros en conjunto. ¿Por qué?

Una posible explicación proviene del hecho de que las ciencias sociales tienen menor demanda, particularmente en un estado donde las actividades industriales y productivas son importantes. En dicho contexto, son las disciplinas vinculadas a las actividades del sector primario y secundario de la economía las que probablemente sean más solicitadas.

El siguiente cuadro muestra el origen departamental de los artículos del Centro de Artes y Humanidades: 


$\begin{array}{llllllllr}\text { Derecho } & - & - & - & 1 & - & - & - & 1 \\ \text { Educación } & 4 & 4 & 1 & 2 & 3 & 1 & 2 & 17 \\ \text { Filosofía } & - & 1 & - & 2 & 3 & - & 2 & 8 \\ \text { Historia } & - & - & - & 4 & 2 & 5 & 1 & 12 \\ \text { Letras } & - & - & - & - & - & - & - & - \\ \text { Psicología } & - & - & - & 2 & 1 & - & 1 & 4 \\ \text { Sociología } & 2 & 1 & 1 & 2 & 1 & 3 & 2 & 12 \\ \text { Tra. Soc. } & - & - & - & - & - & - & 1 & 1 \\ \text { TOTAL } & 6 & 6 & 1 & 13 & 10 & 9 & 9 & 55\end{array}$

Fuente: la misma del cuadro anterior

Del cuadro anterior destacan tres departamentos: en primer lugar, el de Educación, que tiene un arranque sorprendente en los dos primeros años de vida de Investigación y Ciencia, para luego mantener una cantidad estable de artículos publicados. Sin embargo, no debe olvidarse que el departamento de educación, a través del Programa Interinstitucional de Investigaciones sobre Educación (PIIES), tiene un programa editorial propio, del que es resultado una Gaceta y una importante colección de libros.

Los otros departamentos a mencionar son el de Sociología y el de Historia. El primero mantiene una presencia constante de artículos publicados, dinámica que expresa el crecimiento de ese departamento y que son antecedentes que conducirán en 1995 a la creación de una revista propia del Departamento de Sociología.

Simultáneamente, el Departamento de Sociología implementa programas de posgrados con énfasis en sociología de la cultura, población e industrial y del trabajo. Los primeros resultados editoriales empiezan a notarse, recientemente aparecieron dos libros producto de investigaciones enmarcadas en la sociología de la cultura y la sociología industrial y del trabajo.

El Departamento de Historia, con un perfil bajo en los primeros años, despierta a partir de 1993 e iguala en número al de sociología en lo que a artículos publicados se refiere. 
Siguen después, por orden, el Departamento de Filosofía, donde he incluido artículos de profesores visitantes, quienes realizaron su año sabático en la institución; luego el de Psicología donde también se publicó un artículo que fue producto de una estancia sabática, y por último los Departamentos de Derecho y Trabajo Social, con solamente un artículo publicado en los seis años de vida de Investigación y Ciencia. Finalmente, el Departamento de Letras, que no publicó ningún artículo.

\section{El Presente}

Además de las publicaciones ya reseñadas, durante 1995 y hasta la fecha, surgieron dos esfuerzos editoriales departamentales importantes: uno, los Departamentos de Filosofía, Historia y Letras los cuales en forma mancomunada editan Paráfrasis, cuyo primer número es de junio de 1995.

En el editorial del primer número, la revista es presentada como una publicación que tiene como objetivo la divulgación de los conocimientos, las investigaciones y las reflexiones de los docentes e investigadores vinculados a las letras, la filosofía y la historia.

Paráfrasis fue dedicada exclusivamente a temas y tópicos de alguna de las disciplinas ya citadas, aunque los autores y los tipos de artículos publicados fuesen de diferente factura y desigual calidad.

En los números editados, tuvieron cabida avances de investigación de investigadores de alguno de los departamentos; trabajos escolares de estudiantes de posgrado; ponencias de autores extranjeros, artículos de reflexión teórica y reseñas bibliográficas sobre libros de alguna de las tres disciplinas.

Paráfrasis fue concebida como una publicación de difusión de valores humanísticos, definiéndolos como aquellos transmitidos desde la filosofía, es decir el amor a la sabiduría y a la verdad; desde la historia, porque, según el autor del editorial citado, la historia nos permite acrecentar los focos de verdad, y desde la literatu- 
ra porque ésta ha sido, por excelencia, la expresión de nuestro ser americano.

Las definiciones anteriores condujeron a la revista por senderos convencionales y a una errónea política editorial, que orilló al rechazo de algunos artículos.

En esta línea de reflexión es pertinente recordar que las ciencias sociales y las publicaciones vinculadas a temas de lo social, deberían ser la conciencia crítica de la sociedad, de manera que coadyuven a la formación de ciudadanos conscientes y responsables.

Además, en el caso de la definición de la historia como establecedora de verdades eternas e inmutables, me parece un anacronismo, particularmente a la vista del desarrollo que ha tenido en los últimos años.

El resultado fue un conjunto de textos etéreos, que sin pretender formar opinión sobre sucesos contemporáneos, tampoco asumía postura frente a los mismos. Paráfrasis nació y murió sin conocer el pecado. Su vida editorial se caracterizó por una edición irregular y por una limitada distribución local, nacional e internacional.

Hasta la fecha, se han publicado cinco números, más uno en prensa. El siguiente cuadro muestra el número y el origen departamental de los artículos publicados.

$\begin{array}{lc}\text { Disciplina } & \text { junio } \\ \text { Filosofía } & 10 \\ \text { Historia } & 11 \\ \text { Letras } & 12 \\ \text { Otras(a) } & 10 \\ \text { TOTAL } & 43 \\ \text { (a) incluye reseñas y/o noticias académicas. } \\ \text { Fuente: Paráfrasis. }\end{array}$


La revista fue poco conocida afuera del campus, tuvo escasa presencia entre los miembros de la comunidad universitaria y sus ejemplares descansan plácidamente en los libreros esperando un mejor futuro: caer en manos de los lectores.

Mientras que Paráfrasis surge como un proyecto editorial de tres departamentos, en noviembre de 1995 aparece el primer tomo del Anuario de Ciencias Sociales, revista del Departamento de Sociología y Antropología del Centro de Artes y Humanidades.

El Anuario aparece en un volumen por dos tomos de carácter semestral, ya que no pretendía ser una memoria anual del Departamento de Sociología. Sin embargo, no tiene un orden por volumen editado, lo que confunde al citar cada tomo -con igual numeración romana- pero de diferente año.

Esta revista se define como una publicación hecha para el intercambio y el debate, particularmente necesario por las condiciones actuales del país.

Pero, además, Anuario se propuso un objetivo más ambicioso, formar un puente con instituciones académicas de otras latitudes y, fomentar la calidad de los trabajos de estudiantes de licenciatura, abriendo sus páginas para los noveles investigadores, iniciativa que después impulsó Paráfrasis.

El Anuario de Ciencias Sociales se preocupó por incluir temáticas actuales, de manera que los artículos fuesen instrumentos de análisis, definiendo a las disciplinas no como las humanísticas que transmiten valores como la sabiduría, la identidad o la verdad, sino reformulando las definiciones y convirtiéndolas en herramientas de utilidad práctica.

¿Quiénes publican en Anuario de Ciencias Sociales?

La respuesta a esta pregunta, puede ser dada por los estudiantes, colegas extranjeros e investigadores nacionales. No obstante, frente a la diversidad de autores, esto podría tomarse también como limitante para publicar en semejante publicación; ¿Por qué? 
La primera pregunta puede responderse afirmando que, publicar en una revista interdisciplinaria, con una difusión local, nacional e internacional aceptable, garantiza que las reflexiones de los autores sean leídas y conocidas por académicos de otros lugares.

Anuario de Ciencias Sociales tuvo una regular difusión, distribuyéndose en la red de bibliotecas públicas del Estado, adscritas al Instituto Cultural de Aguascalientes, se envió a Estados Unidos, Centroamérica, Europa y universidades y centros de educación superior y/o de documentación en México.

La segunda interrogante se responde por los cambios acelerados que está experimentando la educación superior en el país, y envuelta en esa vorágine por la situación que enfrentan los académicos y las publicaciones. Posiblemente publicar en Anuario -y en Paráfrasis- no garantiza puntos ni promociones, pero si permite llegar a un público más amplio.

Los artículos publicados en el Anuario, cubren una variedad de regiones, temáticas y disciplinas, avances de investigación, resúmenes de capítulos de tesis doctorales y artículos que abordan temas dolorosos y desafortunadamente actuales, que algunos piensan ya superados en las nuevas sociedades modernas y aburridas, sin conflictos ni lucha de clases, en los umbrales del fin de la historia.

El siguiente cuadro, reúne a las disciplinas y su frecuencia de publicación en ACS: 


$\begin{array}{lc}\text { Disciplina } & \text { noviembre } 1995 \text { mayo } 1997 \\ \text { Antropología } & 3 \\ \text { Comunicación } & 2 \\ \text { Derecho } & 1 \\ \text { Economía } & 1 \\ \text { Educación } & 4 \\ \text { Geografía } & 1 \\ \text { Historia } & 6 \\ \text { Sociología } & 18 \\ \text { Otros(a) } & 2 \\ \text { TOTAL } & 38 \\ \text { (a) incluye reseñas bibliográficas y documentos } \\ \text { Fuente: Anuario de Ciencias Sociales 1996-1997 }\end{array}$

La revista de ciencias sociales del Departamento de Sociología dio cabida a temáticas provenientes de diferentes disciplinas. Entre ellos destaca el número creciente y constante de artículos rela- cionados con la Sociología de la Cultura.

Los rituales en la educación, las actitudes ante la muerte, el análisis literario, el elemento simbólico en la arquitectura, los bailes como rituales de redención y los estudios de género, constituyen la veta en la que los estudiantes del posgrado de la cultura, cavan en busca del significado de la conducta humana.

Los artículos sobre demografía aparecieron en el primer tomo del año en curso, al igual que los temas vinculados a la sociología industrial y del trabajo, pero la presencia de trabajos escolares de la licenciatura en Sociología y en Historia, abrió un espacio editorial importante para los estudiantes.

Los proyectos editoriales reseñados líneas arriba, no son excluyentes de las nuevas políticas editoriales de la Universidad. Sin embargo la misma institución debe caminar por un sendero que le permita encontrar sus propias posiblidades editoriales, que si bien deben proponerse altos índices de calidad académica, no deben soslayar el contexto local en que se desenvuelve. 
El proceso de investigación y la publicación de resultados de calidad, parciales o totales, puede ser en algunos casos, producto de una vocación natural de un académico, pero generalmente, es fruto de un desarrollo intelectual que requiere transitar de una etapa de formación -de estudiante- a otra superior, donde la práctica de la profesión es insustituible.

El historiador Roger Chartier afirma que el autor propone, pero el lector dispone de acuerdo a un orden mental, la interpretación y el orden de los libros. De igual forma, es el lector del Aguascalientes de hoy, quien reelabora las palabras y los textos. En función de esa hipótesis fueron escritas las páginas anteriores.

$* * * * * *$

Los esfuerzos editoriales reseñados líneas arriba fueron y son meritorios. La movilización de recursos, necesaria para impulsar aquellas revistas, ha involucrado a profesores y a estudiantes, e incluso al Departamento Editorial de la Universidad. Su esfuerzo no ha caído en el vacío, las revistas que hasta ahora la Universidad ha cobijado han trascendido la imitación.

La polémica y la crítica, la confluencia del reportaje de investigación con los ensayos de corte académico, las secciones sobre América Latina, que nos recuerdan que ningún país vive aislado, son algunos de los rasgos que auguran una larga y fértil vida a una nueva publicación en la Universidad.

Pero fundamentalmente, las páginas abiertas para que la comunidad universitaria dialogue y encuentre formas democráticas de convivencia, donde priven la razón, el diálogo y la consulta. 